\title{
NORVALINE ACCUMULATION BY REGULATORY MUTANTS OF SERRATIA MARCESCENS
}

\author{
Masahiko Kisumi, Masaki Sugiura, Tsutomu Takagi \\ and ICHIRo Chibata \\ Research Laboratory of Applied Biochemistry, Tanabe Seiyaku Co., Ltd., \\ Osaka 532, Japan
}

(Received for publication October 1, 1976)

\begin{abstract}
A gene coding for desensitized L-threonine dehydratase was transduced with phage PS20 into a leucine accumulator of Serratia marcescens Sr41. The transductant converted L-threonine to $\alpha$-ketobutyrate, a precursor of both norvaline and isoleucine. An isoleucinevaline auxotroph of the transductant accumulated large amount of norvaline from Lthreonine as well as from D-threonine.
\end{abstract}

Norvaline is known as an antagonist of branched-chain amino acids ${ }^{1,2)}$ and as a component of an antifungal peptide produced by Bacillus subtilis ${ }^{8}$. We found that norvaline is synthesized from $\alpha$-ketobutyrate by the leucine biosynthetic enzymes in Serratia marcescens, and formation of norvaline is regulated by leucine, but not by narvaline itself ${ }^{4,5}$. [As $\alpha$-ketobutyrate is a precursor of isoleucine, biosynthesis of norvaline is closely related with branched-chain amino acid biosynthesis. We revealed that the isoleucine-valine biosynthetic enzymes were multivalently repressed by isoleucine, valine, and leucine ${ }^{6)}$ and that the leucine biosynthetic enzymes were repressed by leucine ${ }^{7)}$. It was also reported that $\mathrm{L}$-threonine dehydratase was subjected to feedback inhibition by isoleucine ${ }^{8)}$, and that $\alpha$-isopropylmaleate synthetase was feedback-inhibited by leucine ${ }^{7)}$ (see Fig. 1). D-Threonine is readily converted to $\alpha$-ketobutyrate by $\mathrm{D}$-threonine dehydratase $^{8)}$. Accordingly an isoleucine-valine auxotroph of a leucine accumulator, which was released from both feedback inhibition and repression in leucine biosynthesis, could ac-

Fig. 1. Regulatory mechanisms of norvaline, isoleucine, valine and leucine biosynthesis in Serratia marcescens.

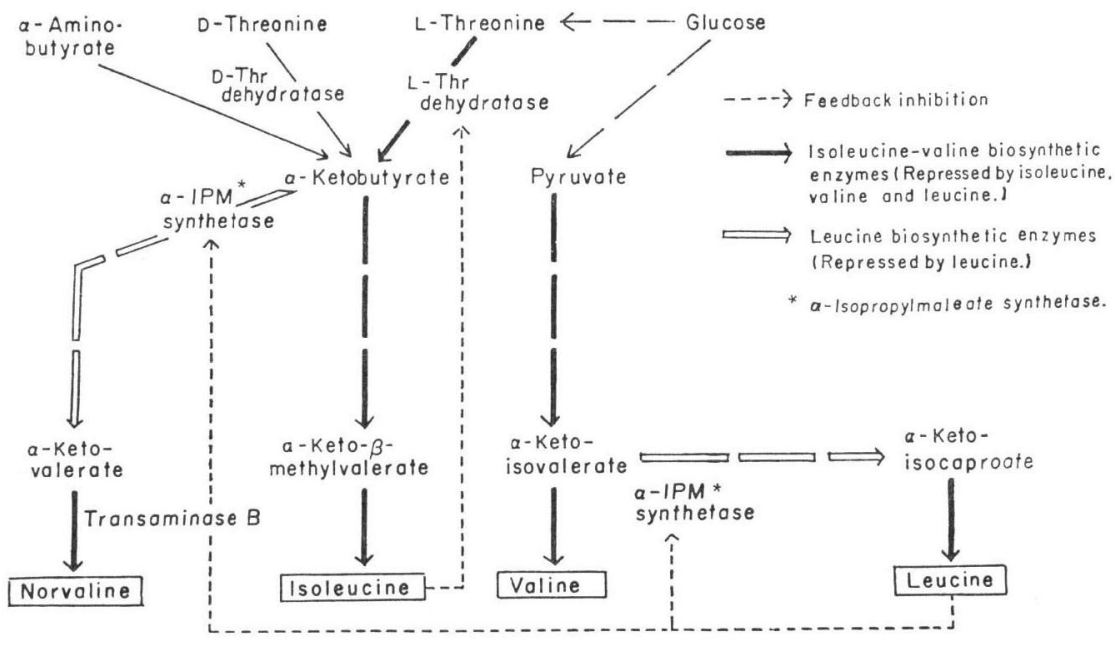


cumulate norvaline from D-threonine or $\alpha$-aminobutyrate ${ }^{5)}$. However, the leucine accumulator lacks L-threonine dehydratase which converts L-threonine to $\alpha$-ketobutyrate, and can not accumulate norvaline from L-threonine. To obtain a mutant which accumulates norvaline from L-threonine, we transduced a gene, coding for desensitized L-threonine dehydratase, into the leucine accumulator, and obtained an isoleucine-valine auxotroph from the transductant. This paper deals with the norvaline accumulation from L-threonine by the isoleucine-valine auxotroph.

\section{Materials and Methods}

Bacteria

Serratia marcescens strain $\mathrm{Sr} 41^{8)}$ and its mutants described in Table 1 were used. Strain Sr41 and a temperate phage PS20 were provided by Dr. H. MAtsumoto (Shinshu University, Matsumoto).

Isolation of mutants

$\alpha$-Aminobutyrate or isoleucine hydroxamate-resistant mutants were isolated from strain $\mathrm{Sr} 41$, following treatment with $\mathrm{N}$ methyl-N'-nitro-N-nitrosoguanidine in the same way described previously ${ }^{2},{ }^{10)}$. Strain AI-1213B, a leucine accumulator, was derived from an isoleucine auxotroph of $\alpha$-aminobutyrate-resistant mutant in the same way described by Kisumi et $a l^{7)}$.

Transduction experiments

Transduction experiments were carried out by a modified method of MATSUMOTO et al..$^{\text {p) }}$ as follows: The phage lysate was prepared by the soft agar-layer method. A culture of donor strain grown on nutrient broth (Difco)

Table 1. Serratia marcescens mutants used.

\begin{tabular}{|c|c|c|}
\hline Strain & Parent strain & Characteristics \\
\hline Sr41 & & (wild) \\
\hline Ar5450 & Sr41 & abu-r* \\
\hline 7135 & Sr41 & ile $\cdot h d x-r^{* *}$ \\
\hline AI-12 & Ar5450 & abu-r, Ile ${ }^{-}$ \\
\hline AI-1213B & AI-12 & abu-r, Ile ${ }^{ \pm}$ \\
\hline AI-IV-9 & AI-1213B & abu-r, $\mathrm{Ile}^{-}, \mathrm{Val}^{-}$ \\
\hline $\mathrm{T}-7767$ & $\begin{array}{l}7135 \text { (donor) } \\
\text { AI-1213B } \\
\text { (recipient) }\end{array}$ & $\begin{array}{l}\text { abu-r, ile } \cdot \text { hdx-r } \\
\text { (transductant) }\end{array}$ \\
\hline T-IV-65 & $\mathrm{T}-7767$ & $\begin{array}{l}\text { abu-r, ile } \cdot h d x-r \text {, } \\
\text { Ile- }^{-} \text {, Val- }\end{array}$ \\
\hline
\end{tabular}

* $\alpha$-Aminobutyrate-resistant.

** Isoleucine hydroxamate-resistant. was mixed with the appropriate amount of the phage PS20 solution, and incubated for 10 hours at $30^{\circ} \mathrm{C}$ in a soft agar $(0.7 \%$ agar $)$ nutrient medium. The soft agar layer of a plate was suspended in $3 \mathrm{ml}$ of the nutrient broth and crushed by blending, and the suspension was centrifuged at $7,000 \mathrm{rpm}$ for 10 minutes at $4^{\circ} \mathrm{C}$. The phage lysate was obtained in the form of the resulting supernatant. One $\mathrm{ml}$ culture broth of the recipient strain grown on nutrient medium (about $10^{8}$ cells $/ \mathrm{ml}$ ) was mixed with $5 \mathrm{ml}$ of the phage lysate that contained about $2 \times 10^{\circ}$ p.f.u. $/ \mathrm{ml}$, and the mixture was kept at $30^{\circ} \mathrm{C}$ for 30 minutes to allow phage adsorption. The mixture was then centrifuged at 3,000 rpm for 10 minutes, and the sediment was resuspended in saline. One-tenth $\mathrm{ml}$ of the sample was spread on an agar plate containing a modified minimal medium of DAvis and MingIoli ${ }^{11)}$. The medium lacked citrate, and contained $0.5 \%$ glucose and $1 \mathrm{mg} / \mathrm{ml}$ of isoleucine hydroxamate. The plate was incubated at $30^{\circ} \mathrm{C}$ for 72 hours. After incubation, large colonies were picked and purified on selective plates. Frequency of transduction (numbers of isoleucine hydroxamate-resistant transductants per survival cells) was about $3 \times 10^{-7}$.

Media and culture conditions

The fermentation medium contained $2 \%$ glucose, $10 \%$ dextrin (Matsutani Chemical Co., \#3), $1 \%$ urea, $0.1 \% \mathrm{~K}_{2} \mathrm{HPO}_{4}, 0.05 \% \mathrm{MgSO}_{4} \cdot 7 \mathrm{H}_{2} \mathrm{O}, 0.7 \%$ corn steep liquor, and $2 \% \mathrm{CaCO}_{3}$ $(\mathrm{pH}$ 7.0). D-Threonine or L-threonine was added to the medium at concentrations of $20 \sim 30$ $\mathrm{mg} / \mathrm{ml}$. Isoleucine, valine, and leucine were added at levels of $0.2 \sim 2 \mathrm{mg} / \mathrm{ml}$. Glucose and dextrin were autoclaved separately, and added to the medium. A loopful of cells, which had been grown overnight on nutrient agar, was inoculated into $15 \mathrm{ml}$ of the medium in a $500-\mathrm{ml}$ flask. Incubation was carried out at $30^{\circ} \mathrm{C}$ for 72 hours with reciprocal shaking $(140 \mathrm{rpm}, 8-\mathrm{cm}$ 
stroke).

Preparation of cell-free extracts

The bacteria were grown in a $500-\mathrm{ml}$ flask containing $150 \mathrm{ml}$ of the modified DAvis-MingIOLI medium at $30^{\circ} \mathrm{C}$ with shaking. When strain AI-1213B or strain AI-12 was cultured, $25 \mu \mathrm{g} / \mathrm{ml}$ of isoleucine was added to the medium. The cells were harvested at the exponential growth phase and washed twice with $0.05 \mathrm{~m}$ tris-(hydroxymethyl)-aminomethane hydrochloride (Tris- $\mathrm{HCl}$ ) buffer. Cell-free extracts were prepared by the method of KIsumi et al. ${ }^{5}$ ), and immediately used for the enzyme assays. Protein was determined by the method of Lowry et al. ${ }^{12)}$.

Enzyme assays

L-Threonine dehydratase was assayed by the method of Kisumi et al. ${ }^{2)} \quad \alpha$-Isopropylmaleate synthetase reaction was performed with $\alpha$-ketobutyrate and acetyl-CoA using the method of Kisumi et al. ${ }^{5)}$ Transaminase $\mathrm{B}$ was assayed as follows: The reaction mixture contained 20 $\mu$ moles of L-norvaline, $20 \mu$ moles of sodium $\alpha$-ketoglutarate, $0.4 \mu$ moles of pyridoxal phosphate, $100 \mu$ moles of potassium phosphate buffer ( $\mathrm{pH} 8.0)$, cell-free extract $(0.3 \sim 1.0 \mathrm{mg}$ of protein), and the total volume of reaction mixture was brought to $1.0 \mathrm{ml}$. After $15 \sim 30$-minute incubation at $37^{\circ} \mathrm{C}$, the reaction was stopped by heating. Then, L-glutamic acid formed was assayed microbiologically using Leuconostoc mesenteroides P-60. Specific activities were expressed as $\mu$ moles of products per $\mathrm{mg}$ of protein per minute.

Other analytical methods

Isoleucine and leucine were determined microbiologically using Leuconostoc mesenteroides P-60. Norvaline and norleucine were determined spectrophotometrically by extraction of paperchromatogram as described by KISUmi et al. ${ }^{4)}$ A Hitachi KLA-3B amino acid analyzer was also employed to determine the unnatural amino acids. Growth of the organism was estimated by measuring the optical density at $660 \mathrm{~nm}$ of fermentation broth diluted with $0.1 \mathrm{~N} \mathrm{HCl}$, and expressed as dry cell weight calculated from a standard curve.

\section{Results}

Isolation of a Leucine Accumulator

A leucine accumulator, strain AI-1213B, was isolated from Serratia marcescens strain Sr41 using the procedure of Kisumi et al. ${ }^{5)}$ In an $\alpha$-aminobutyrate-resistant mutant, strain Ar5450, the leucine biosynthetic enzymes as well as the isoleucine-valine biosynthetic enzymes were genetically derepressed (Table 2). However, the $\alpha$-isopropylmaleate synthetase was subjected to feedback inhibition by leucine. An isoleucine auxotroph (L-threonine dehydratase-deficient mutant), strain AI-12, was derived from strain Ar5450. In an isoleucine leaky revertant, strain AI-1213B, which was derived from strain AI-12, feedback inhibition of $\alpha$-isopropylmaleate synthetase was released without reversion of L-threonine dehydratase. Therefore, in strain AI-

Table 2. Lack of feedback controls of leucine biosynthetic enzymes in strain AI-1213B.

\begin{tabular}{l|c|c|c|c|c}
\hline \multirow{2}{*}{ Strain } & \multicolumn{2}{|c|}{ L-Threonine dehydratase } & \multicolumn{2}{c|}{$\alpha$-Isopropylmaleate synthetase } & \multicolumn{2}{c}{ Transaminase B } \\
\cline { 2 - 5 } & S.A.* & Inhibition (\%)** & S.A.* & Inhibition (\%)*** & S.A.* $^{*}$ \\
\hline Sr41 (wild) & 0.18 & 95 & 0.01 & 90 & 0.06 \\
Ar5450 (abu-r) & 0.50 & 96 & 0.11 & 92 & 0.43 \\
AI-12 (abu-r, Ile ${ }^{-}$) & 0 & - & 0.09 & 90 & 0.35 \\
AI-1213B (abu-r, Ile ${ }^{ \pm}$) & 0 & - & 0.09 & 5 & 0.34 \\
\hline
\end{tabular}

* Specific activity ( $\mu$ moles products formed $/ \mathrm{min} / \mathrm{mg}$ of protein).

** Inhibition by L-isoleucine $10^{-3} \mathrm{M}$.

*** Inhibition by L-leucine $10^{-2} \mathrm{M}$. 
Table 3. Accumulation of isoleucine, leucine and norvaline by strains AI-1213B and AI-IV-9.

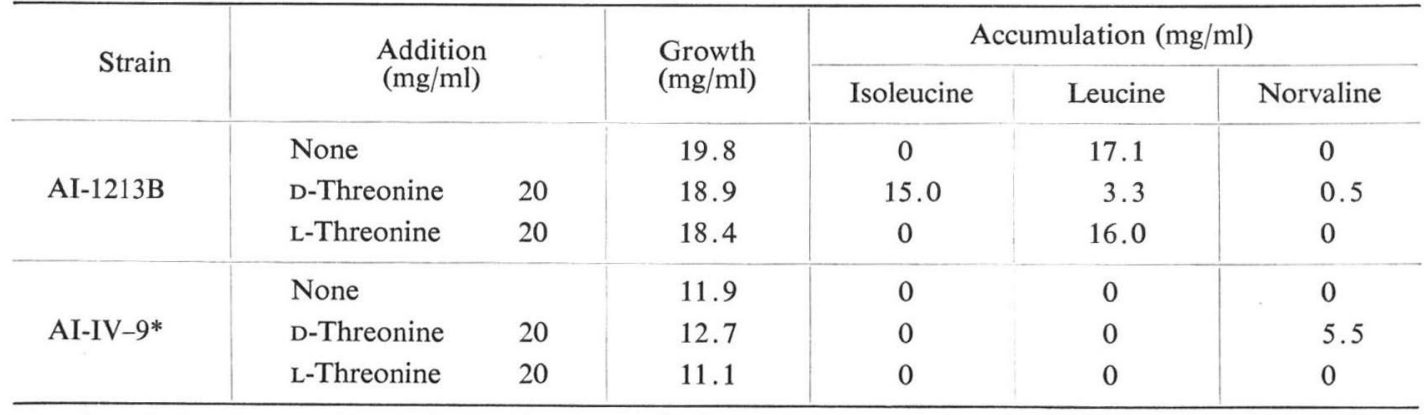

* L-Isoleucine, L-valine and L-leucine were added at $0.5,1.0$ and $0.2 \mathrm{mg} / \mathrm{ml}$ to the medium.

1213B, both feedback inhibition and repression of leucine biosynthesis were released. Strain AI-1213B accumulated leucine and isoleucine, when D-threonine was added to the medium (Table 3). However, this strain did not accumulate isoleucine when L-threonine was added, due to the lacking of L-threonine dehydratase. Thereafter, an isoleucine-valine auxotroph, strain AI-IV-9, was isolated from the leucine accumulating strain AI-1213B. The auxotroph did not accumulate norvaline from L-threonine, but accumulated it from D-threonine.

Isolation of Mutants Desensitized in L-Threonine Dehydratase

We found that $\mathbf{L}$-threonine dehydratase was released from feedback inhibition by isoleucine in the isoleucine hydroxamate-resistant mutants ${ }^{10)}$. An isoleucine hydroxamate-resistant mutant, strain 7135, was derived from strain Sr41. In strain 7135, L-threonine dehydratase was released from feedback inhibition by isoleucine, but regulations of other enzymes were not altered (Table 4).

Table 4. Properties of isoleucine hydroxamate-resistant mutant, strain 7135.

\begin{tabular}{l|c|c|c|c|c}
\hline \multirow{2}{*}{ Strain } & \multicolumn{2}{|c|}{ L-Threonine dehydratase } & \multicolumn{2}{c|}{$\alpha$-Isopropylmaleate synthetase } & \multicolumn{2}{c}{ Transaminase B } \\
\cline { 2 - 6 } & S.A.* & Inhibition (\%)** & S.A.* & Inhibition (\%)*** & S.A.* \\
\hline Sr41 (wild) & 0.18 & 90 & 0.01 & 90 & 0.06 \\
7135 (ile·hdx-r) & 0.26 & 10 & 0.01 & 92 & 0.06 \\
\hline
\end{tabular}

* Specific activity ( $\mu$ moles products formed $/ \mathrm{min} / \mathrm{mg}$ of protein).

** Inhibition by L-isoleucine $10^{-3} \mathrm{M}$.

*** Inhibition by L-leucine $10^{-2} \mathrm{M}$.

Transduction of Isoleucine Hydroxamate-Resistance into the Leucine Accumulator

To isolate a mutant which is not only derepressed but also desensitized in both L-threonine dehydratase and $\alpha$-isopropylmaleate synthetase, transduction of isoleucine hydroxamate-resistance into the leucine accumulator was investigated. In a transductant, strain T-7767, L-threonine dehydratase was released from feedback inhibition by isoleucine as in the donor strain 7135, and $\alpha$-isopropylmaleate synthetase was also desensitized as in the recipient strain AI-1213B. L-Threonine dehydratase of the transductant was derepressed to the same level of the $\alpha$-aminobutyrate-resistant mutant, strain Ar5450 (Table 5). Strain T-7767 accumulated isoleucine from L-threonine as well as from D-threonine, and produced norvaline as a by-product (Table 6). This result indicates that strain $\mathrm{T}-7767$ converts not only D-threonine but also L-threonine 
Table 5. Lack of feedback controls of isoleucine and leucine biosynthetic enzymes in strain T-7767.

\begin{tabular}{l|c|c|c|c|c}
\hline \multirow{2}{*}{ Strain } & \multicolumn{2}{|c|}{ L-Threonine dehydratase } & \multicolumn{2}{c|}{$\alpha$-Isopropylmaleate synthetase } & Transaminase B \\
\cline { 2 - 6 } & S.A.* & Inhibition (\%)** & S.A.* & Inhibition (\%)*** & S.A.* \\
\hline 7135 (donor) & 0.26 & 10 & 0.01 & 90 & 0.06 \\
AI-1213B (recipient) & 0 & - & 0.09 & 5 & 0.34 \\
T-7767 (transductant) & 0.41 & 12 & 0.08 & 3 & 0.35 \\
\hline Ar5450 & 0.49 & 90 & 0.10 & 90 & 0.41 \\
\hline
\end{tabular}

* Specific activity ( $\mu$ moles products formed $/ \mathrm{min} / \mathrm{mg}$ of protein).

** Inhibition by L-isoleucine $10^{-3} \mathrm{M}$.

*** Inhibition by L-leucine $10^{-2} \mathrm{M}$.

Table 6. Accumulation of isoleucine and leucine by strain T-7767.

\begin{tabular}{|c|c|c|c|c|c|}
\hline \multirow{2}{*}{\multicolumn{2}{|c|}{$\begin{array}{l}\text { Addition } \\
(\mathrm{mg} / \mathrm{ml})\end{array}$}} & \multirow{2}{*}{$\begin{array}{l}\text { Growth } \\
(\mathrm{mg} / \mathrm{ml})\end{array}$} & \multicolumn{3}{|c|}{ Accumulation $(\mathrm{mg} / \mathrm{ml})$} \\
\hline & & & Isoleucine & Leucine & Norvaline \\
\hline None & & 18.9 & 1.0 & 15.4 & 0 \\
\hline D-Threonine & 30 & 18.4 & 14.8 & 1.5 & 0.4 \\
\hline L-Threonine & 30 & 20.4 & 11.3 & 2.6 & 0.3 \\
\hline
\end{tabular}

Table 7. Accumulation of norvaline by strain T-IV-65.*

\begin{tabular}{|c|c|c|c|c|c|c|c|c|}
\hline \multirow{3}{*}{$\begin{array}{l}\text { Addition } \\
(\mathrm{mg} / \mathrm{ml})\end{array}$} & \multirow{2}{*}{\multicolumn{2}{|c|}{ Growth $(\mathrm{mg} / \mathrm{ml})$}} & \multicolumn{6}{|c|}{ Amino acids (mg/ml) } \\
\hline & & & \multicolumn{2}{|c|}{ Norvaline } & \multicolumn{2}{|c|}{ Norleucine } & \multicolumn{2}{|c|}{ Threonine } \\
\hline & $48 \mathrm{hr}$ & $72 \mathrm{hr}$ & $48 \mathrm{hr}$ & $72 \mathrm{hr}$ & $48 \mathrm{hr}$ & $72 \mathrm{hr}$ & $48 \mathrm{hr}$ & $72 \mathrm{hr}$ \\
\hline None & 11.3 & 12.1 & 0.5 & 0.8 & 0.2 & 0.3 & 0 & 0 \\
\hline D-Threonine 20 & 11.8 & 12.7 & 4.7 & 7.1 & 1.2 & 1.3 & 6.3 & 4.6 \\
\hline L-Threonine 20 & 13.3 & 15.6 & 4.2 & 7.4 & 1.1 & 1.3 & 4.8 & 3.8 \\
\hline
\end{tabular}

* L-Isoleucine, L-valine and L-leucine were added at $0.5,1.0$ and $0.2 \mathrm{mg} / \mathrm{ml}$ to the medium.

to $\alpha$-ketobutyrate, a precursor of both isoleucine and norvaline.

\section{Norvaline Accumulation}

Since strain T-7767 is capable of converting L-threonine to $\alpha$-ketobutyrate, it would accumulate norvaline by blocking the conversion of $\alpha$-ketobutyrate to isoleucine. An isoleucinevaline auxotroph, strain T-IV-65, was isolated from strain T-7767. When strain T-IV-65 was incubated for 72 hours in a medium containing D- or L-threonine, norvaline was accumulated over $7 \mathrm{mg} / \mathrm{ml}$. Norleucine was formed as a by-product by strain T-IV-65, but isoleucine and leucine were not formed. The strain T-IV-65 also accumulated a small amount of norvaline in the medium without the addition of threonine (Table 7).

\section{Discussion}

To obtain a norvaline accumulator from L-threonine, a leucine accumulator and a mutant desensitized in L-threonine dehydratase were isolated independently. The gene, coding for the desensitized L-threonine dehydratase, was transduced into the leucine accumulator. In the transductant, not only $\alpha$-isopropylmaleate synthetase but also L-threonine dehydratase were 
released from the feedback controls. An isoleucine-valine auxotroph of the transductant accumulated a large amount of norvaline from L-threonine. The auxotroph of the transductant accumulated a small amount of norvaline in the medium without the addition of threonine. Norleucine was also formed as a by-product by the auxotroph of the transductant.

Norvaline and norleucine have been used as antagonists of branched-chain amino acids or methionine. However, little is known about the biosynthesis of these unnatural amino acids. Since some antibiotics contain unnatural amino acids, regulation of unnatural amino acid biosynthesis is of interest in relation to the biosynthesis of the antibiotics. We mentioned that these unnatural amino acids were formed by mediation of the leucine biosynthetic enzymes, and that the formation was regulated by leucine.

In recent years, many amino acids have been produced by fermentative methods using regulatory mutants. Genetic studies, especially of enteric bacteria (Escherichia coli or Salmonella typhimurium), helped the understanding of the regulatory mechanisms in amino acids biosynthesis. Although transduction is an available technique for genetic analysis, no report has appeared on the application of transducing method for the improvement of industrial producers of amino acids, except for that of histidine and urocanic acid production using Serratia marcescens by ours ${ }^{13)}$. As genetic analysis in Serratia marcescens is proceeding gradually $\left.{ }^{9}, 14,15\right)$, the transducing method will be very useful for the improvement of mutants producing amino acids and other metabolites.

\section{Acknowledgements}

We are grateful to Mr. T. TAKAYAnagi, former senior manager of the Research and Development Division of this company, for encouragement. We also thank Mr. F. Murakami and Miss Y. Nonoguchi for technical assistance.

\section{References}

1) Karlström, O.: Methods for the production of mutants suitable as amino acid fermentation organisms. Biotechnol. Bioeng. 7: 245 268, 1965

2) Kisumi, M.; S. Komatsubara \& I. Chibata: Valine accumulation by $\alpha$-aminobutyric acid-resistant mutants of Serratia marcescens. J. Bact. 106: 493 499, 1971

3) NANDi, P. \& G. P. SeN: An antifungal substance from a strain of B. subtilis. Nature 172: 871 872, 1953

4) Kisumi, M.; M. Sugiura, J. Kato \& I. Chibata: L-Norvaline and L-homoisoleucine formation by Serratia marcescens. J. Biochem. 79: 1021 1028, 1976

5) Kisumi, M.; M. Sugiura \& I. Chibata: Biosynthesis of norvaline, norleucine, and homoisoleucine in Serratia marcescens. J. Biochem. 80: 333 339, 1976

6) Kisumi, M.; S. Komatsubara \& I. Chibata: Multivalent repression and genetic derepression of isoleucinevaline biosynthetic enzymes in Serratia marcescens. J. Bact. 107: 824 827, 1971

7) Kisumi, M.; S. Komatsubara \& I. Chibata: Leucine accumulation by isoleucine revertants of Serratia marcescens resistant to $\alpha$-aminobutyric acid: Lack of both feedback inhibition and repression. J. Biochem. 73: 107 115, 1973

8) Kisumi, M.; Y. Ashikaga, J. Kato \& I. Chibata: Studies on the isoleucine fermentation. II. On the mechanism of isoleucine formation and threonine dehydratase. J. Biochem. 52: 400 408, 1962

9) Matsumoto, H.; T. Tazaka \& S. Hosogaya: A generalized transducing phage of Serratia marcescens. Jap. J. Microbiol. 17: 473 479, 1973

10) Kisumi, M.; S. Komatsubara, M. Sugiura \& I. Chibata: Properties of isoleucine hydroxamateresistant mutants of Serratia marcescens. J. Gen. Microbiol. 69: 291 297, 1971

11) Davis, B. D. \& E. S. Mingroli: Mutants of Escherichia coli requiring methionine or vitamin $B_{12}$. J. Bact. $60: 17 \sim 18,1950$

12) Lowry, O. H.; M. J. Rosebrought, A. L. Farr \& R. J. Randall: Protein measurement with the Folin phenol reagent. J. Biol. Chem. 193: 265 275, 1951

13) Kisumi, M.; N. Nakanishi, T. Takagi \& I. Chibata: Derivation of histidine and urocanic acid producers by transduction of Serratia marcescens. Abstr., Ann. Meet. Agr. Chem. Soc. Japan (in 
Japanese), p. 30, 1975

14) Stamminger, G.; M. Brendel \& R. W. Kaplan: Co-transduction mapping in Serratia marcescens. Zeit. Allg. Mikrobiol. 13: 59 70, 1973

15) Matsumoto, H.; S. Hosogaya, K. Suzuki \& T. Tazaki: Arginine gene cluster of Serratia marcescens. Jap. J. Microbiol. 19: 35 44, 1975 